\title{
Eco-Design of the Urban Corridor in View of the Landscape Ecological Theory
}

\author{
Hao Kaili1 ${ }^{1, a}$, Liang Yan $^{2, b^{*}}$ \\ ${ }^{1}$ Department of Environmental Design, Lanzhou Jiaotong University,Anning District, Lanzhou, Gansu Province, China \\ ${ }^{2}$ Department of Environmental Design, Lanzhou Jiaotong University,Anning District, Lanzhou, Gansu Province, China
}

\begin{abstract}
Benefiting from the rapid development of global economy, a growing number of post-industry products spring up. In comparison to the population in the suburb, the urban population presents a significantly increasing tendency. Undoubtedly, the efficient lifestyle, the convenient way of traveling and the industrial products have caused irresistible threat and damage to the nature. The soil desertification, saline-alkali land, forest degradation and else environmental issues occur as an obvious warning from the nature to us. Therefore, it is an imminent research subject at the moment to seek for symbiotic and harmonious relationship between the human and the nature. The urban landscape is a type of highly artificial design. In it, the urban corridor develops to steer the development of the overall urban landscape pattern. In the process of urban corridor design, the landscape ecological theory is essential in practical application. Spirited by ecological design, the natural ecology landscape is added on the basis of artificial restoration. This paper profoundly studied the sustainable development of the urban landscape setup, thus providing healthier and livelier design on the green ecological corridor for the urban dwellers.
\end{abstract}

\section{Explanation for the Concept and Principle of the Landscape Ecology}

It is indisputable that the landscape ecology, a new subject which combines ecology with geography, yet which is distinguished from the two subjects, creates a separate researching target. It is a branch of science that studies the setup, process and variation of the landscaping. In accordance with Foreman's standpoint, "at the beginning of landscape ecology, there isn't any other theory that can explain the spatial heterogeneity of energy, nutrition, substance, water, plants and animals in terms of landscape." That is, the landscape ecology is a "live" organic system, and it is complete. Thereupon, as the research target of landscape ecology, it focuses on relatively larger scale of multiple ecosystems as well as concentrates on studying the interaction on a horizontal dimension. This also explains that the mature development of landscape ecology possesses certain research foundation.

By means of comprehension on the structure of "landscape patch-corridor-substrate", the integrated ecological network was programmed to highlight the spatial heterogeneity and diversity of its landscape. As a modern landscape designer, he should take into account of the urban sustainability as well as the way of balancing the pros and cons in view of "people oriented" and "ecology restoration". Therefore, the author regards that it is very necessary to further study the landscape ecology.

\section{Theory and Content of Urban Ecological Corridor Construction in the View of Landscape Ecology}

\subsection{Content of Urban Ecological Corridor Construction}

"Ecological corridor" is a significant belt that links the planning frontier of urban landscape and the overall construction of city appearance. The purpose of integrating the eco-design idea into the urban corridor construction is to improve the stability of the whole urban landscape system. In the process of construction, it is essential to increase the plant diversity on the basis of plant allocation to unblock the eco-corridors and strengthen the stability of ecosystem. The Jiangtan Park at the west bank of Xiangjiang River in Changsha city (Figure 1) is a perfect case. It built the ecological 


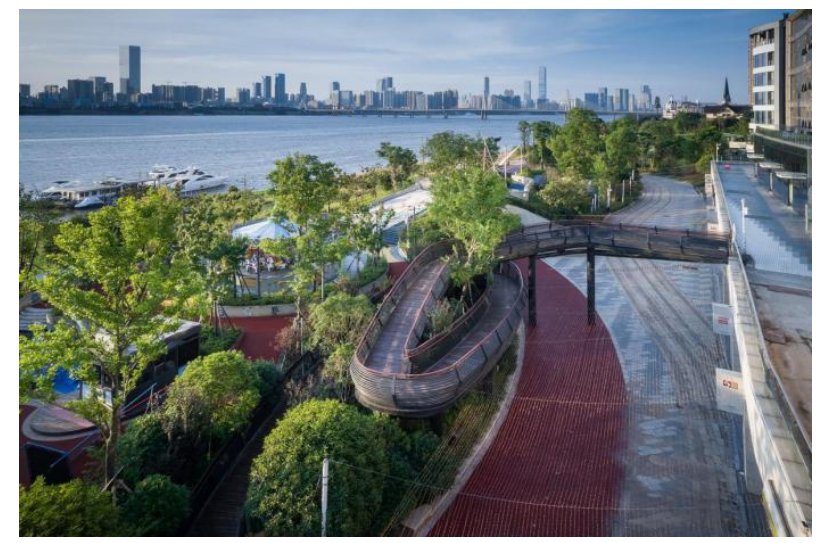

Figure 1 Restoration of the ecological corridor (The picture is from the Internet)

corridor to restore river erosion. Moreover, the landscape selected some local plant varieties as the scenic forest belt to enrich the landscape plant gradation. Through topographic allocation of plants, it perfectly improved the biological diversity on the sites and provided favorable habitats for the birds, fish and mollusk. In combination of the plant ecology and the water conservation in river corridor, the whole set of dynamic landscape had constituted a complete eco-corridor. It is obvious that, as artificial restoration reaches certain threshold, other factors in the biological chain will make up a healthy circle. As the masters in the city, the "humans" are not only the contributors who restore the ecology to healthy balance; we are also the largest beneficiary for the gift of nature.

Today, high buildings stand in the city everywhere. The highly artificial city landscape has already flooded into our lives. The overwhelming building patches and corridors occupy so many land resources that it causes air pollution, declines of water quality, climate warming and a series of natural disasters; comparatively, the green field patches and corridors are rarely seen. Although there are corridor regions, however, the width of ecological corridors doesn't conform to the standard. The seriously shrunk eco-corridors have brought about soil erosion, chaotic planning on regional grids and a host of problems. Therefore, at the same time of building greenbelt corridor, it is supposed to pay attention to the planning of the blue river corridors. The existing river courses on site can be used to rationally add the waterfront space in light of the local conditions. This is favorable to speed up the heat exchange of water, green plants, the air and other natural things. As a result, it repays a healthy ecosystem and improves the human comfort level.

\subsection{Theory of Urban Eco-Corridor Construction}

The urban eco-corridor is a type of corridor that possesses service functions such as protecting the biological diversity, filtering pollutant, preventing soil erosion, realizing sand fixation, controlling flood and so on. Hereby the mentioned urban eco-corridor refers to the "landscaping construction-type corridor" . It primarily aims to increase the regional landscape quality, instruct the sustainability of ecological construction as well as improve people' $\mathrm{s}$ life happiness index. The main structure of the eco-corridor is mostly linear or band-shaped. It is the landscape belt which is located in the adjacent environmental spaces. In addition to dividing the urban landscape, the eco-corridor is also the major route that connects various landscape elements. In terms of corridor construction, it should be noted that, the eco-corridor cannot be built among the clustered multi-storey buildings. Meanwhile, the buildings need use semi-permeable structure to improve their correspondence [1] to the corridors.

As science and technology develops rapidly, the stress of urban life increases as the days pass on. The fast-paced and intense work state presses people out of breath. The whole city falls into a sub-health status. Therefore, the eco-design should be used to forge the urban corridors and connect the landscape to alleviate the trouble. Adhering to the principle of "ecology first, minimum intervention, humane integration and people orientation", along with breaking through the conventions in the past, the eco-design creates sufficient space for the growth and development of natural landscape while emphasizing on artificial landscaping. As a result, on the basis of ensuring ecological functions, it fulfills the aesthetic perception [1] by using the landscape ecology theory. On all aspects, the eco-design lays a foundation for promoting the urban ecological construction.

\section{Application of the Landscape Ecology on Urban Eco-Corridor Design}

\subsection{Proposal on the Design of Urban Eco-Corridor under Landscape Ecology}

\subsubsection{Building the Demonstration Area of Ecological Corridor, Consolidating the Community of Natural Life}

The report of the 19th National Congress of the Communist Party of China shows that, "Optimize the system of ecological safety barrier, build the protection network for eco-corridor and biological diversity as well as improve the quality and stability of ecological system." There is no doubt that, the eco-corridor construction has been a new prevalent trend. It will 
improve the residential sense of ecology and enlarge their knowledge reservation. Only through the combination of theory and practice, can the ecological landscape design be carried out preferably. It aims to build a sustainably developing community by infusing the eco-design theory into the urban corridor construction, thus realizing the consolidation of natural life and sufficient integration of artificial landscape elements.

\subsubsection{Adhering to the Artificial Restoration of Ecology, Strengthening the Optimization of Ecological Space Setup}

Regarding the separation of ecological units in cities due to deficiency in systematic design, the author holds that, the green corridors and tiny natural patches need increase to promote the material communication at the frontier of patches. Accordingly it will construct suitable area that conforms to the ecological requirements and the sustainably developing landscape. Furthermore, centered by the ecological urban design and green blocks, the safety pattern for the green landscape ecology has been built. By designing the linear ecological belt, it becomes more convenient to connect the ecological belt with other dotted and chunked patches (Figure 2), thus building the symbiosis development of overall urban landscape and promoting the integration of various elements.

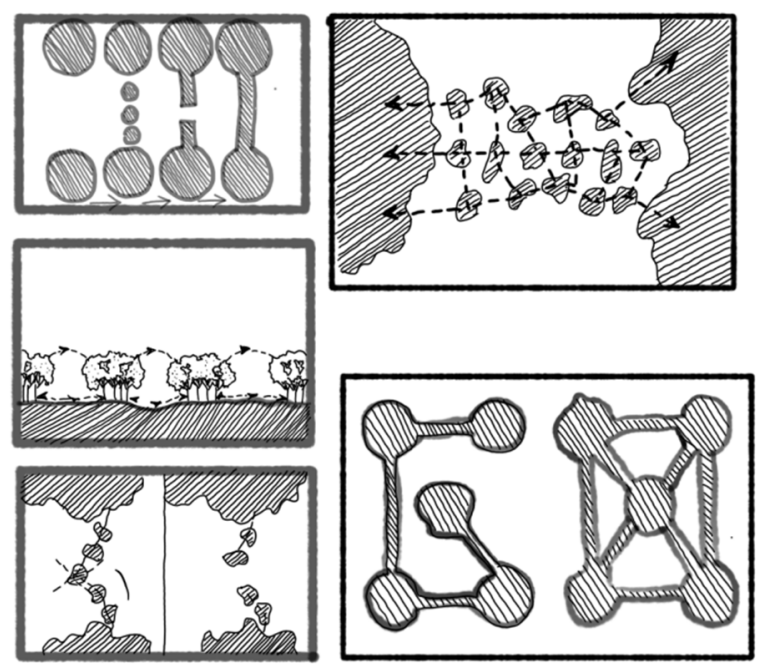

Figure 2 Design of the eco-corridor setup

(The picture is from the Internet)

\subsection{The Effect of Landscape Ecology in Urban Eco-Corridor Design}

As a branch of systematic research disciplines, the landscape ecology takes the idea of "the entirety is greater than the sum of parts" . Any subsystem is an independent and intact individual. It is a type of subordinate relationship between the subsystem and the higher level of system. For the ecological corridor design, it exists as an individual and simultaneously it is involved in the whole urban landscape planning. According to the theory of landscape ecology, when the ecosystem becomes more complicated, such as species diversity, landscape heterogeneity or other increases, its stability will be reinforced. The anti-interference tenacity will also be stronger. Consequently its self-healing capacity will increase as well.

In ancient China, Laozi, the founder of Taoism, proposed that "the law of Tao follows the nature". This ideology is still workable nowadays. The threshold has already been exceeded by excessively human intervention, so we need to give way to the nature. Although artificial landscape is efficient and convenient, it doesn't signify to make the city become better. The principle of "people oriented, ecology first" has been pursued throughout the ecological corridor design. In the overall planning for corridors, it is supposed to preserve the natural landscape area. Only if the ecological design is implemented in priority and further supplemented by the landscape planning, may the symbiosis of human and the nature develop sustainably.

\section{Conclusion}

In today' $\mathrm{s}$ society, the whole cities are plunged into a dangerous situation [3] by the issues of population aggregation, energy consumption, increasing scale of production and economy, along with the continually growth of pollutants. Therefore, urban construction is subject to satisfy the requirements of human activities and also ensure original ecology of plants and animals. Accordingly, the eco-corridor design is extraordinarily important. It can connect the separate areas and shattered space together, transforming them into sustainable, continual, rhythmical and mobile landscape space.

The ecological corridor is like the adhesive that binds other landscape parts of the city together. It integrates them into the natural circulation. The ecological corridor brings the nature back to the city; it brings in the plants and animals, improves the urban ecological environment as well as promotes the overall urban quality by rebuilding affectionate conversation between "the human" and "the nature". 


\section{Reference:}

[1] Liu Cong, Research on the Urban Landscaping Construction in View of Landscape Ecology [J]. Green Technology, 2020 (19): P37-P38.

[2] Zhang Tao, Michael- Grover. Thoughts on the Landscape Designing Context: Merge of Design, Ecology, Tenacity and Research [J], Landscape Design, 2018 (04): P54-P62.

[3] Wu Nan, Wu Sihao. Research on the Planning and Design of Urban Ecological Park in the View of Landscape Ecology [J]. Chinese and Overseas Architecture, 2020 (6): P148-P150. 